Emma L. Moynihan, Teagasc, Crops Environment and Land-Use Department, Environmental Research Centre, Johnstown Castle, Wexford, County Wexford, Ireland and Cranfield University, School of Applied Sciences, Cranfield, Bedfordshire, MK43 OAL, UK; Karl G. Richards and Fiona P. Brennan (corresponding author; email: Fiona.brennan@ hutton.ac.uk), Teagasc, Crops Environment and Land-Use Department, Environmental Research Centre, Johnstown Castle, Wexford, County Wexford, Ireland; Karl Ritz and Sean F. Tyrrel, Cranfield University, School of Applied Sciences, Cranfield, Bedfordshire, MK43 OAL, UK.

Cite as follows: Moynihan, E.L., Richards, K.G., Ritz, K., Tyrrel, S.F. and Brennan, F.P. 2013 Impact of soil type, biology and temperature on the survival of nontoxigenic Escherichia coli O157. Biology and Environment: Proceedings of the Royal Irish Academy 113B. DOI: 10.3318/ BIOE.2013.05.

Received 16 July 2012. Accepted 31 August 2012. Published 10 June 2013.

\title{
IMPACT OF SOIL TYPE, BIOLOGY AND TEMPERATURE ON THE SURVIVAL OF NON-TOXIGENIC ESCHERICHIA COLI O157
}

\author{
Emma L. Moynihan, Karl G. Richards, Karl Ritz, \\ Sean F. Tyrrel and Fiona P. Brennan
}

\begin{abstract}
The occurrence of microbial enteropathogens in the environment can represent a serious risk to human health. The fate of enteropathogens introduced into the soil environment is dependent on a wide range of complex interacting environmental factors. While the effect of abiotic factors on enteropathogen survival has been widely examined, the interaction of enteropathogens with the soil microbial community is poorly understood. This study investigated the effect of soil biology and soil type on the survival of a non-toxigenic strain of Escherichia coli O157 under different temperature regimes. Soil microcosms of two soil types, with and without an intact microbial community, were inoculated with the enteropathogen surrogate, and survival was determined over a 64-day period, encompassing a shift from cold to ambient temperatures. In both soil types bacterial numbers decreased in soil with an intact microflora, while in the absence of an intact community E. coli populations increased. This effect was temperature specific, with E. coli populations remaining stable at low temperature, regardless of treatment. Soil type was of importance in survival at both cold and ambient temperatures. This work highlights the significance of the soil microbial community in suppressing enteropathogens in soil, and of investigating die-off in a multi-factorial manner.
\end{abstract}

\section{INTRODUCTION}

The occurrence of microbial enteric pathogens in the environment can represent a serious risk to human health. While numerous sources of pathogenic microorganisms have been identified in the environment, agriculture is often implicated as a significant contributor (Vernozy-Rozand et al. 2002; Burton and Turner 2003; Duffy 2003). Enteropathogens, including pathogenic bacteria, viruses, protozoa and helminths, may be released in large numbers in faecal material, deposited either directly by grazing animals or indirectly by the landspreading of animal manures, slurries and soiled waters (Gerba and Smith 2005; Chadwick et al. 2008). Among the principal pathogens of concern from agricultural sources is Vero cytotoxigenic Escherichia coli (VTEC), a subset of the enterohaemorrhagic E. coli (EHEC) group, which is highly pathogenic, has a low infectious dose and can cause severe illness in humans (Willshaw et al. 1994; EFSA 2007). The majority of human illness is caused by the O157 serotype, which can induce bloody diarrhoea and haemolytic uraemic syndrome (HUS), potentially resulting in renal failure and haemolytic anaemia (Porter et al. 1997). Ruminant animals, particularly cattle, constitute the primary reservoir of VTEC among livestock (Chapman et al. 1997; Nicholson et al. 2005). Once introduced into the environment VTEC can be transmitted to new human and animal hosts through direct contact with contaminated faeces or by ingestion of faecally contaminated food and water.

Survival times and die-off rates of enteropathogens in soils are critical for assessment of the risk posed to human populations by agricultural activities, with natural decay of pathogenic microbes in soil helping to prevent further transmission of infectious disease (Rosen 2000; Lang et al. 2003). Soil environments which favour prolonged survival and/or growth of enteropathogens can act as reservoirs for the subsequent contamination of disease vectors such as crops or water. The fate of enteropathogens introduced into the soil environment is dependent on a wide range of complex interacting environmental factors. These include the physical, chemical and biological properties of the soil, such as $\mathrm{pH}$, soil moisture status, predation, soil type, nutrient availability, 
soil structure and oxygen status (Sjogren 1995; Ishii et al. 2007; Semenov et al. 2008). Although there is extensive literature examining the effect of abiotic factors on enteropathogen survival in soil, studies investigating the impact of biotic factors, and particularly the soil microbial community, on survival are not as common (Jiang et al. 2002; van Elsas et al. 2007; 2012), and therefore the interaction of enteropathogens with the indigenous microflora is poorly understood. Biotic interactions that may affect survival include antagonism from indigenous microorganisms, competition for resources, predation and occupation of niche space (van Elsas et al. 2002). These biotic interactions would likely be strongly affected by both soil type and temperature. The effect of soil type and soil community status on $E$. coli survival in the context of a shift in temperature has not been previously investigated.

The objective of this experiment was to determine the effect of soil biology on the survival of a non-toxigenic strain of E. coli O157 in two soil types under different temperature regimes. The fate of E. coli $\mathrm{O} 157$ was investigated in relation to a shift from cold to ambient temperatures. This was carried out to approximate springtime conditions when livestock manures are applied. It was hypothesised that: (1) the indigenous soil microbial community would reduce $E$. coli survival as the soil community is better adapted to compete more effectively for space and nutrients; (2) the effect of the indigenous soil community on E. coli persistence would be temperature and soil-type dependent, with greater survival at low temperatures when the native community is metabolically less active, and in soils with a higher clay content, which would provide the $E$. coli with protection from predation and potential nutrient sources.

\section{MATERIALS AND METHODS}

\section{SOIL COLLECTION AND PREPARATION}

Two contrasting soil types from the Bearsted and Evesham series, both classified as Cambisols according to the World Reference Base (WRB 2006), were used in this experiment: (i) Bearsted soil $(52.0075 \mathrm{~N}, 0.4352 \mathrm{~W})$, a typical brown earth, described as coarse loamy passing to sandstone, pH 6.07 and C:N ratio of 10.6; (ii) Evesham soil $(52.0048 \mathrm{~N}, 0.4324 \mathrm{~W})$ a typical calcareous pelosol, described as clayey passing to clay or soft mudstone, $\mathrm{pH} 6.6$ and $\mathrm{C}: \mathrm{N}$ ratio 13.9. Replicate microcosms consisting of $5-\mathrm{g}$ aliquots of each soil were prepared in $30-\mathrm{ml}$ sterile glass vials for E. coli persistence incubations. Soil samples were collected to a depth of $0.15 \mathrm{~m}$ from grass field margins that had not received livestock manure, or been grazed, within the previous 10 years. Soil was sieved to $4 \mathrm{~mm}$, mixed, and the water-holding capacity (WHC) was determined for each soil type according to the method described by Franz et al. (2011). Moisture content was then adjusted so that soils exhibited similar cohesiveness to achieve standard friability between different soil types, by wetting-up or restricted slow drying on the bench as appropriate. Following adjustment, soil moisture was measured by oven-drying at $105^{\circ} \mathrm{C}$ for $24 \mathrm{~h}$, and expressed as a percentage of WHC. This was determined to be $25 \%$ and $44 \%$ of the WHC for the sand loam and clay loam soils, respectively. For each soil type, sterile and non-sterile microcosms were established, providing an extreme contrast of soil biological communities. Soil microcosms were sterilised by autoclaving twice over a 2-day period $\left(121^{\circ} \mathrm{C}\right.$ for $1 \mathrm{~h}$ at $\left.1 \mathrm{bar}\right)$. The remaining non-sterile microcosms had an intact microbial community. For each soil type, two treatments (sterile and non-sterile) were tested in independent triplicate replicates on each of seven sampling dates. Uninoculated microcosms for each treatment were used as a background control.

\section{INOCULATION AND SURVIVAL ANALYSIS}

Soil microcosms were inoculated with $1 \times 10^{8}$ colony-forming units (CFU) of E. coli O157:H7 strain 3704. This is a non-toxigenic VTEC strain originally isolated from the environment (Campbell et al. 2001). The inoculum was prepared by streaking a loopful of glycerol stock culture onto a Sorbitol MacConkey agar plate and incubating at $37^{\circ} \mathrm{C}$ for $24 \mathrm{~h}$. A colony was then picked from the plate and inoculated into $100 \mathrm{ml}$ Luria-Bertani (LB) broth, which was incubated as previously on an orbital shaker at $120 \mathrm{rpm}$. An aliquot of $100 \mu \mathrm{l}$ was then transferred to fresh LB broth, and incubated a second time. This final $E$. coli culture was then spun down and washed three times with $1 / 4$ strength Ringer's solution (Oxoid) prior to inoculation within a volume of $500 \mu 1$. After inoculation microcosms were incubated at $4^{\circ} \mathrm{C}$ for the first six days of the experimental period, and at $18^{\circ} \mathrm{C}$ thereafter. This temperature regime was chosen to simulate livestock manure application during a cold period followed by a period of warming, which would be typical of spring conditions in Ireland. All microcosms were mixed gently by hand following inoculation. Soil microcosms were incubated for up to 64 days and were destructively sampled immediately after inoculation, and on days $2,4,8,16,32$ and 64 of the experimental period. Microcosms 
were monitored for evaporation by weighing, and sterile water was added when necessary to maintain moisture levels. The extraction efficiencies (based on time 0 sampling time) for these soils were determined to be $58 \%$ and $83 \%$ for the clay loam and sand loam, respectively. Escherichia coli concentrations in the microcosms were enumerated by adding $10 \mathrm{ml}$ sterile $1 / 4$ strength Ringer's solution, vortexing for $1 \mathrm{~min}$ and oscillating on a rotary shaker at $150 \mathrm{rpm}$ for $15 \mathrm{~min}$. Microcosms were then vortexed a second time and allowed to stand for $5 \mathrm{~min}$. The supernatant was serially diluted using $1 / 4$ strength Ringer's solution and plated on MacConkey sorbitol agar amended with cefixime-tellurite (Oxoid) using the spread plate technique. Plates were incubated at $37^{\circ} \mathrm{C}$ for $24 \mathrm{~h}$ and characteristic beige colonies of non-toxigenic E. coli O157 were counted (Avery et al. 2005).

\section{STATISTICAL ANALYSIS}

The interactions between temperature, treatment (sterile/non-sterile) and time were analysed as a 2 $\times 2 \times 7$ factorial design, with soil type as a blocking factor. The Mixed Procedure in SAS (V9.1) was used to determine the effect of soil type, treatment and time interactions on E. coli $\mathrm{O} 157$ survival. All assumptions of the analyses were met. Values obtained at $4^{\circ} \mathrm{C}$ and at $18^{\circ} \mathrm{C}$ were analysed separately, to investigate $E$. coli response to warming temperatures that may be encountered during spring land applications. Soil types were also analysed separately to determine the effect of treatment over time. Finally, this procedure was used to determine the effect of the interaction between treatment and incubation temperature on survival. Multiple comparison post hoc analyses were performed with the Tukey honestly significant difference test. Mean CFU values were also used in Statistica (Version 10) to calculate the death rate (k-value) for $E$. coli in non-sterile sand loam and clay loam during incubation at $18^{\circ} \mathrm{C}$. The first order decay function $\left[\mathrm{y}=\mathrm{a}+\mathrm{b}^{\star} e^{-\mathrm{kt}}\right.$, where y represents the population at a given time $\left(\log \mathrm{CFU} \mathrm{g}{ }^{-1}\right.$ soil), a represents stability of the final population at the end of the experiment ( $\log$ CFU g ${ }^{-1}$ soil), b was the difference in population between the beginning and end of the experiment ( $\log \mathrm{CFU} \mathrm{g}^{-1}$ soil), $\mathrm{k}$ represents the rate of population decline $\left(\right.$ days $\left.^{-1}\right)$, t represents time (days)] was used. This function has been used previously to estimate pathogen decay rates (Mubiru et al. 2000; Oliver et al. 2006). This function did not fit the population growth observed in the sterile microcosms so a linear function was instead applied to these treatments.

\section{RESULTS}

The persistence of the E. coli O157 (strain 3704) within the two soil types in both sterile and nonsterile microcosms is shown in Fig. 1. Overall,

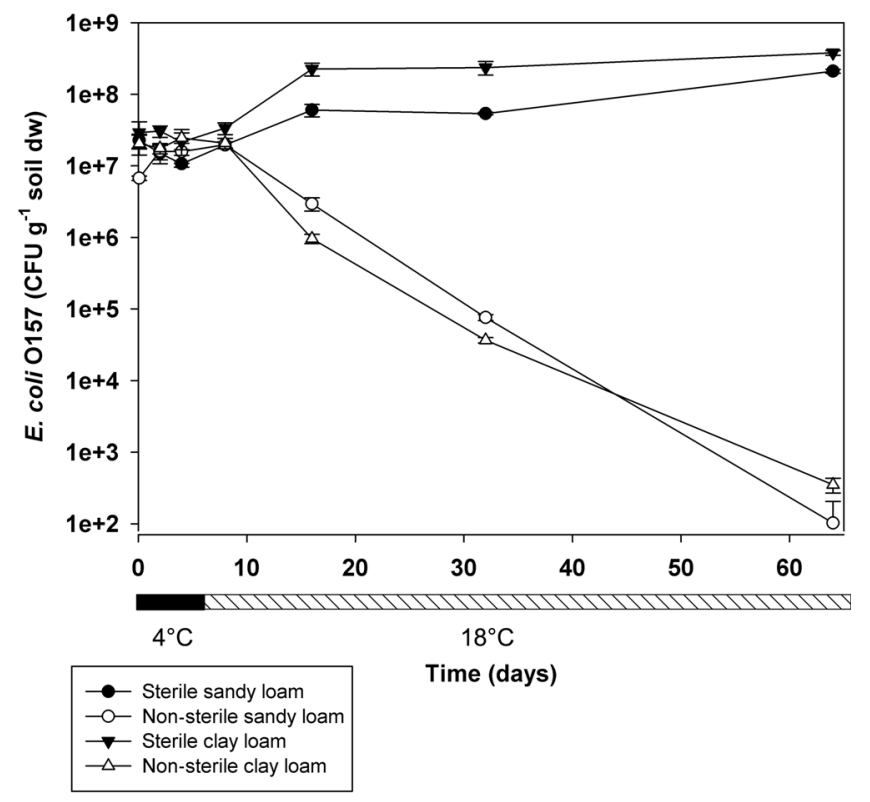

Fig. 1-Survival of Escherichia coli $\mathrm{O} 157$ in sterile and non-sterile sand loam and clay loam microcosms. Points denote mean CFU $(n=3)$; error bars denote standard error (note that some error bars fall within confines of symbols). Temperature is represented by the bar below the $x$-axis. 
E. coli concentrations increased in sterile soil with the absence of an intact microbial community, while concentrations decreased in non-sterile soil. Escherichia coli concentrations were stable at $4^{\circ} \mathrm{C}$, and while the $F$ statistic (6.07) for soil type indicated a strong blocking effect at this temperature, there was no significant effect ( $\alpha=0.05)$ of time, treatment, or their interaction with soil type on survival. When the incubation temperature was increased to $18^{\circ} \mathrm{C}$, however a significant $(P<0.0001)$ three-way interaction was observed. In both soil types, a lag period was observed following the temperature change (day 6) before a difference between treatments became apparent, as there was no significant difference between sterile and non-sterile soils on day 8 .

In sterile soil, E. coli populations increased in both sand loam and clay loam soils during the incubation at $18^{\circ} \mathrm{C}$. This increase was significant initially $(P<0.0001)$; however, populations stabilised toward the end of the experiment. There was no significant difference in $E$. coli concentration in the clay loam soil between day 16 and 64 at $18^{\circ} \mathrm{C}$. Similarly, there was no significant difference in E. coli concentration in the sand loam soil between day 16 and 32 at $18^{\circ} \mathrm{C}$; however, E. coli increased significantly thereafter until the final sampling date on day $64(P<0.0001)$. Overall, there was a significant increase in $E$. coli concentrations in both soil types between day 8 and 64 at $18^{\circ} \mathrm{C}(P<$ 0.0001). In non-sterile soil, E. coli populations decreased in both soil types during incubation at $18^{\circ} \mathrm{C}$. This decrease was maintained throughout, and was significant between each sampling interval for both soil types $(P<0.0001)$. There was also a significant effect of the treatment by temperature interaction on $E$. coli survival $(P<0.0001)$, but there was no difference in this effect between soil types. The interaction was significant for all combinations of treatments and temperatures with the exception of non-sterile and sterile soils during incubation at $4^{\circ} \mathrm{C}$. Similarly, there was no significant effect of this interaction between sterile soils incubated at $4^{\circ} \mathrm{C}$ and $18^{\circ} \mathrm{C}$.

Death rates were calculated for E. coli during incubation at $18^{\circ} \mathrm{C}$ and were found to be $0.24 \mathrm{day}^{-1}$ and $0.36 \mathrm{day}^{-1}$ in non-sterile sand loam and clay loam soils, respectively. Corresponding growth rates in sterile systems (calculated from the slope) were found to be $1.27 \mathrm{day}^{-1}$ and $1.71 \mathrm{day}^{-1}$ in sand loam and clay loam soils, respectively.

\section{DISCUSSION}

A fundamental effect of the indigenous microbial community on E. coli survival was strongly supported by the data presented here with the pathogen being found to grow in sterile soil in the absence of a microbial community, but dieoff observed where the soil community remained intact. However, this treatment effect was temperature specific, being only observed at $18^{\circ} \mathrm{C}$ with $E$. coli concentrations remaining stable at low temperature, irrespective of soil biotic status. The observed decrease at $18^{\circ} \mathrm{C}$ was likely caused by enhanced activity of indigenous soil microorganisms and resultant antagonism toward the introduced pathogen. The effect of temperature on interactions between the pathogen and the soil community has been reported previously. Jiang et al. (2002) observed a more rapid decline of E. coli $\mathrm{O} 157$ in manure-amended unautoclaved soil at $21^{\circ} \mathrm{C}$ than at $5^{\circ} \mathrm{C}$. This was attributed to an increase in microbial activity with temperature and consequently, greater competition for nutrients. Similarly, Vidovic et al. (2007) found that E. coli $\mathrm{O} 157$ declined more rapidly at $22^{\circ} \mathrm{C}$ compared to $4^{\circ} \mathrm{C}$ in unautoclaved soil. Predation of introduced $E$. coli by the soil community may have also played a role in the observed decline in nonsterile soil at $18^{\circ} \mathrm{C}$. Sørensen et al. (1999) found that an introduced strain of $E$. coli $\mathrm{K} 12$ persisted in soil for $70 \mathrm{~d}$ at $4^{\circ} \mathrm{C}$ and $10^{\circ} \mathrm{C}$; however, it was no longer detectable after $20 \mathrm{~d}$ at $25^{\circ} \mathrm{C}$. The decline in E. coli K12 occurred with a corresponding increase in indigenous soil flagellates and ciliates. Similarly, Recorbet et al. (1992) noted that a decrease in the concentration of introduced $E$. coli coincided with an increase in the indigenous amoeba population.

An increase in $E$. coli concentration was observed in sterile soils in the absence of competitive and predatory interactions. The sterilisation process can alter the physical and chemical environment of the soil. Razavi and Lakzian (2007) found a significant increase in the concentration of extractable organic carbon in autoclaved soil as compared to a control using the chloroform fumigation extraction (CFE) technique. This increase was attributed to the breakdown of humic substances and the death of microorganisms. Also, Unc and Goss (2006) observed a significant increase in the number of $E$. coli in manure-amended sterile soil. This was because of not only the elimination of competitors and predators during sterilisation, but also the extra carbon released by cell lysis. In this case, the additional carbon may have served as a significant food source for the pathogen.

Soil type is another important aspect of pathogen survival, as different soils have unique biogeochemical, structural and textural properties that determine the availability of substrate, water and habitats. It was hypothesised that 
greatest persistence and growth would be observed in non-sterile and sterile clay loam microcosms, respectively, compared to corresponding sand loam microcosms, and this was supported by the data presented here. Soil type was a significant factor affecting pathogen survival at $18^{\circ} \mathrm{C}$ in this study. Typically survival is positively associated with clay content because of inherent clay properties such as fine texture (Cools et al. 2001), micropore availability (Postma et al. 1990; Wright et al. 1995) and nutrient adsorption (Coleman et al. 2004). For example, Fenlon et al. (2000) could isolate exogenous E. coli for four months from clay and loam soils compared with eight weeks from sand soils. Additionally, Franz et al. (2008) showed a negative association between E. coli O157:H7 survival and number of clay particles in manure-amended loamy soils. However, contrary to the original hypothesis, this experiment found that E. coli decayed more rapidly in clay loam soil. Other work has shown that organic matter (OM) can be more influential than soil texture in determining pathogen survival (Cools et al. 2001; Lang and Smith 2007). Therefore, persistence in sand loam soil in this instance may have been because of the confounding effect of differences in soil OM and microbial community composition between soil types. Nonetheless, the greatest absolute numbers of $E$. coli were isolated from the clay loam soil at the end of the experimental period, thus confirming the importance of clay in long-term E. coli persistence, which has been previously described (Brennan et al. 2010). Additionally, the highest growth rate was achieved in clay loam soil. This was likely caused by greater nutrient availability associated with clay content, which may have facilitated a more rapid expansion of the E. coli population.

To conclude, E. coli introduced to cold soils through springtime application of livestock manure may form an environmental reservoir, persistent whilst such conditions prevail. However, based on these results, this reservoir may be depleted as temperatures increase if the native community is intact. However, if the native community has been compromised, this reservoir may potentially increase with increasing temperatures as the result of competition for nutrients and antagonistic interactions. This shows the importance of a healthy soil microbial community for effective pathogen suppression, and of investigating die-off in a multi-factorial manner.

\section{ACKNOWLEDGEMENTS}

The authors gratefully acknowledge Teagasc for the funding provided through the Walsh
Fellowship Scheme and the Teagasc Post-Doctoral Fellowship Scheme. The authors also wish to thank Dr Lisa Avery, James Hutton Institute, UK for the provision of the E. coli strain and Dr Jim Grant for assistance with the statistical analysis.

\section{REFERENCES}

Avery,L.M., Killham, K. and Jones, D.L. 2005 Survival of E. coli O157:H7 in organic wastes destined for land application. Journal of Applied Microbiology 98, 814-22.

Brennan, F.P., O'Flaherty, V., Kramers, G., Grant, J. and Richards, K.G. 2010 Long-term persistence and leaching of Escherichia coli in temperate maritime soils. Applied and Environmental Microbiology 76, 1449-55.

Burton, C.H. and Turner, C. 2003 Manure management. Treatment for sustainable agriculture. $2 \mathrm{nd}$ ed. Bedford, UK. Silsoe Research Institute.

Campbell, G.R., Prosser, J., Glover, A. and Killham, K. 2001 Detection of Escherichia coli O157:H7 in soil and water using multiplex PCR. Journal of Applied Microbiology 91, 1004-10.

Chadwick, D., Fish, R., Oliver, D.M., Heathwaite, L., Hodgson, C. and Winter, M. 2008 Management of livestock and their manure to reduce the risk of microbial transfers to water - the case for an interdisciplinary approach. Trends in Food Science and Technology 19, 240-7.

Chapman, P.A., Siddons, C.A., Cerdan Malo, A.T. and Harkin, M.A. 1997 A 1-year study of Escherichia coli $\mathrm{O} 157$ in cattle, sheep, pigs and poultry. Epidemiology and Infection 119, 245-50.

Coleman, D.C., Crossley, D.A. and Hendrix, D.F. (2004) Fundamentals of soil ecology. 2nd ed. San Diego, CA. Elsevier Academic Press.

Cools, D., Merckx, R., Vlassak, K. and Verhaegen, J. 2001 Survival of E. coli and Enterococcus spp. derived from pig slurry in soils of different texture. Applied Soil Ecology 17, 53-62.

Duffy, G. 2003 Verocytoxigenic Escherichia coli in animal faeces, manures and slurries. Journal of Applied Microbiology 94, 94S-103S.

EFSA. 2007 Scientific opinion of the panel on biological hazards on a request from EFSA on monitoring of verotoxigenic Escherichia coli (VTEC) and identification of human pathogenic VTEC types. The EFSA Journal 579, 1-61.

Fenlon, D.R., Ogden, I.D., Vinten, A. and Svoboda, I. 2000 The fate of Escherichia coli and E. coli O157 in cattle slurry after application to land. Symposium series (Society for Applied Microbiology) 29, 149S-56S

Franz, E., Semenov, A.V., Termorshuizen, A.J., De Vos, O.J., Bokhorst, J.G. and van Bruggen, A.H.C. 2008 Manure-amended soil characteristics affecting the survival of E. coli $\mathrm{O} 157: \mathrm{H7}$ 
in 36 Dutch soils. Environmental Microbiology 10 313-27.

Franz, E., van Hoek, A.H.A.M., Bouw, E. and Aarts, H.J.M. 2011 E. coli strain variability in manure-amended soil in relation to strain origin, virulence profile and carbon nutrition profile. Applied and Environmental Microbiology 77, 8088-96.

Gerba, C.P. and Smith Jr, J.E. 2005 Sources of pathogenic microorganisms and their fate during land application of wastes. Journal of Environmental Quality 34, 42-8.

Ishii, S., Hansen, D.L., Hicks, R.E. and Sadowsky, M.J. 2007 Beach sand and sediments are temporal sinks and sources of Escherichia coli in Lake Superior. Environmental Science and Technology 41, 2203-9.

Jiang, X., Morgan, J. and Doyle, M.P. 2002 Fate of Escherichia coli O157:H7 in manure-amended soil. Applied and Environmental Microbiology 68, 2605-9.

Lang, N.L., Smith, S.R., Bellett-Travers, D.M., Pike, E.B. and Rowlands, C.L. 2003 Decay of Escherichia coli in soil following the application of biosolids to agricultural land. Journal of the Chartered Institution of Water and Environmental Management 17, 23-8.

Lang, N.L. and Smith, S.R. 2007 Influence of soil type, moisture content and biosolids application on the fate of Escherichia coli in agricultural soil under controlled laboratory conditions. Journal of Applied Microbiology 103, 2122-31.

Mubiru, D.N., Coyne, M.S. and Grove, J.H. 2000 Mortality of Escherichia coli O157:H7 in two soils with different physical and chemical properties. Journal of Environmental Quality 29, 1821-5.

Nicholson, F.A., Groves, S.J. and Chambers, B.J. 2005 Pathogen survival during livestock manure storage and following land application. Bioresource Technology 96, 135-43.

Oliver, D.M., Haygarth, P.M., Clegg, C.D. and Heathwaite, A.L. 2006 Differential E. coli die-off patterns associated with agricultural matrices. Environmental Science \& Technology 40, 5710-6.

Porter, J., Mobbs, K., Hart, C.A., Saunders, J.R., Pickup, R.W. and Edwards, C. 1997 Detection, distribution and probable fate of Escherichia coli O157 from asymptomatic cattle on a dairy farm. Journal of Applied Microbiology 83, 297-306.

Postma, J., Hok-Hin, A.C.H. and Van Veen, J.A. 1990 Role of microniches in protecting introduced Rhizobium leguminosarum biovar trifolii against competition and predation in soil. Applied and Environmental Microbiology 56, 495-502.

Razavi, S. and Lakzian, A. 2007 Evaluation of chemical and biological consequences of soil sterilisation methods. Caspian Journal of Environmental Science 5, 87-91.
Recorbet, G., Steinberg, C., and Faurie, G. 1992 Survival in soil of genetically engineered Escherichia coli as related to inoculum density, predation and competition. FEMS Microbiology Ecology 101, 251-60.

Rosen, B. 2000 Waterborne pathogens in agricultural watersheds. US Department of Agriculture, Watershed Science Intsitute, Vermont.

Semenov, A., Franz, E., van Overbeek, L., Termorshuizen, A.J. and van Bruggen, A.H.C. 2008 Estimating the stability of Escherichia coli O157:H7 survival in manureamended soils with different management histories. Environmental Microbiology 10, 1450-9.

Sjogren, R.E. 1995 Thirteen-year survival study of an environmental Escherichia coli in field miniplots. Water, Air, E Soil Pollution 81, 315-35.

Sørensen, S.J., Schyberg, T. and Rønn, R. 1999 Predation by protozoa on Escherichia coli K12 in soil and transfer of resistance plasmid RP4 to indigenous bacteria in soil. Applied Soil Ecology 11, 79-90.

Unc, A. and Goss, M.J. 2006 Culturable Escherichia coli in soil mixed with two types of manure. Soil Science Society of America Journal 70, 763-9.

van Elsas, J.D., Garbeva, P. and Salles, J. 2002 Effects of agronomical measures on the microbial diversity of soils as related to the suppression of soil-borne plant pathogens. Biodegradation 13, 29-40.

van Elsas, J.D., Hill, P., Chronakova, A., Grekova, M., Topalova, Y., Elhottova, D. and Kristufek, V. 2007 Survival of genetically marked Escherichia coli O157:H7 in soil as affected by soil microbial community shifts. ISME J 1, 204-14.

van Elsas, J.D., Chiurazzi, M., Mallon, C.A., Elhottova, D., Kristufek, V. and Salles, J.F. 2012 Microbial diversity determines the invasion of soil by a bacterial pathogen. Proceedings of the National Academy of Sciences 109, 1159-64.

Vernozy-Rozand, C., Montet, M.P., Lequerrec, F., Serillon, E., Tilly, B., Bavai, C., Ray-Gueniot, S., Bouvet, J., Mazuy-Cruchaudet, C. and Richard, Y. 2002 Prevalence of verotoxin-producing Escherichia coli (VTEC) in slurry, farmyard manure and sewage sludge in France. Journal of Applied Microbiology 93, 473-8.

Vidovic, S., Block, H.C. and Korber, D.R. 2007 Effect of soil composition, temperature, indigenous microflora, and environmental conditions on the survival of Escherichia coli O157:H7. Canadian Journal of Microbiology 53, 822-9.

Willshaw, G., Thirlwell, J., Jones, A., Parry, S., Salmon, R. and Hickey, M. 1994 Vero cytotoxin-producing Escherichia coli O157 in beefburgers linked to an outbreak of diarrhoea, haemorrhagic colitis and haemolytic uraemic syndrome in Britain. Letters in Applied Microbiology 19, 304-7.

WRB. 2006 World reference base for soil resources. World Soil Resources Report No. 103. FAO, Rome. 